\title{
Aesthetic sense and social cognition: a story from the Early Stone Age
}

\section{Greg Currie ${ }^{1}\left[\right.$ Xuanqi Zhu $^{1}$}

Received: 30 April 2019 / Accepted: 11 November 2019 / Published online: 29 November 2019

(c) The Author(s) 2019

\begin{abstract}
Human aesthetic practices show a sensitivity to the ways that the appearance of an artefact manifests skills and other qualities of the maker. We investigate a possible origin for this kind of sensibility, locating it in the need for co-ordination of skill-transmission in the Acheulean stone tool culture. We argue that our narrative supports the idea that Acheulean agents were aesthetic agents. In line with this we offer what may seem an absurd comparison: between the Acheulean and the Quattrocento. In making it we display some hidden complexity in human aesthetic responses to an artefact. We conclude with a brief review of rival explanationsbiological and/or cultural—of how this skills-based sensibility became a regular feature of human aesthetic practices.
\end{abstract}

Keywords Acheulian $\cdot$ Handaxe $\cdot$ Aesthetics $\cdot$ Cultural learning $\cdot$ Hominin cognition

The aim of painting: to give pleasure, good will and fame to the painter, more than

riches.

Alberti, On Painting (Alberti 1435/1970).

\begin{abstract}
A distant ancestor of this paper was given at the conference on Remote Access: The Philosophy, Anthropology, and Archaeology of Remote Visual Conspicuousness, Frei Universitat Berlin, 2018; thanks to Whitney Davis, Marilynn Johnson, Jonas Grethlein, Lambros Malafouris, Sam Rose, Jakub Stejskal and Marilyn Strathern for their comments at the meeting, to Ellen Winner and Penny Spikins for discussion, and to the editors of this special issue of, and two readers for, Synthese.
\end{abstract}

Greg Currie

Gregory.currie@york.ac.uk

Xuanqi Zhu

xuanqi.zhu@york.ac.uk

1 Department of Philosophy, University of York, York YO10 5DD, UK 


\section{Aesthetics and the act of making}

While aesthetics occupies a respectable though modest corner of philosophy, the scholars best placed to apply its results to the human world-anthropologists, archaeologists and art historians - are generally indifferent or hostile to its ideas. ${ }^{1}$ There's a notion abroad that aesthetics celebrates the resources of uncontaminated perceptual experience, isolated from meaning, use, status or anything else of significance. ${ }^{2}$ Yet within contemporary aesthetics this same view is widely rejected exactly because it is unable to do justice to the richness and complexity of aesthetic judgement. ${ }^{3}$ Take for example our sensitivity to the ways an artefact's appearance is a trace of the activity of its makers. A Vermeer and a perfectly executed copy may have exactly the same appearance in the sense that one could not identify the copy simply by comparing their surfaces. But they are not the same aesthetically; we are sensitive to the fact that the appearance of the one is a trace of forms of activity not exemplified in the production of the other. Vermeer made compositional choices not open to the copyist, exhibiting talents not disclosed by the copyist's product. ${ }^{4}$ There may be occasions on which, or people for whom, the manifestation of copying skills are more important than creativity in composition. The point still holds: what we value aesthetically we value at least in part for its manifestation of qualities in the maker. ${ }^{5}$

Does that mean that the Vermeer and the copy do not, after all, look the same, at least when we understand their background differences? Answering that question depends on how widely you draw the boundaries of what can literally be seen. ${ }^{6}$ We don't need to take a stand on that issue. You may think that what is appreciated aesthetically is available in perception alone-the perception-only view; in that case you should say that what is visually represented goes beyond the "low level" properties of shape, colour, size and movement. You may not like that, because you think that vision, strictly conceived, encompasses only the low level properties - the narrow conception of what can be seen; in that case you should say that

\footnotetext{
1 But see below, text to note 16 .

${ }^{2}$ For an example of the aesthetic narrowly understood see Coleman (2004): “... with highly symbolic works, an inability to comprehend meaning does not appear to impede our aesthetic sense at all". For criticism of views of this kind see Currie (2012); for a convergent assessment see Rose (2017).

3 See Walton (1970) for a classic statement of this rejection.

4 There are aspects of our comparative valuing of these pictures_-particularly financial valuing-which reflect factors other than their values as traces. But trace-value is one important factor.

5 This relation to the perception of skill is widely recognised in the aesthetics literature. Frank Sibley noted that "as we come to realize how boldly or subtly, with what skill, economy, and exactness, the effect is achieved, how each detail is judged to a nicety and all work together with a fine precision, our appreciation is deepened and enriched" (Sibley 2001, p. 37; from a paper first published in 1965). Kendall Walton says “...the reader may also appreciate, he may admire with pleasure, the poet's perceptiveness and insightfulness and her skill in presenting profound truths in a vivid and convincing manner. Then the reader's enjoyment is (in part at least) aesthetic" (Walton 1993, p. 55); Stephen Davies says "recognition of the beauty distinctive to a representation might be inseparable from an appreciation of the techniques of depiction" (Davies 2006, pp. 235-236). Dutton (1979) is a systematic and influential statement of this sort of view.

${ }^{6}$ Helton (2016) is a review of this fast-moving field.
} 
aesthetic sensibility is not confined to the purely perceptual. ${ }^{7}$ Neither view is intrinsically improbable. Whether perception should be characterised narrowly or widely we leave undecided. All we insist on is a rejection of the narrow conception of the aesthetic, according to which the bounds of the aesthetic are the bounds of perception narrowly conceived.

Our positive account starts from the idea that artefacts display, through their aesthetic properties, the skills, sensibilities and sometimes personality traits that contributed to the fashioning of those very properties. Our intensely social evolution has made us exquisitely sensitive to properties of these kinds, and their manifestation in artefacts creates and sustains powerful affective and cognitive relations (including the good will noted by Alberti) between observers and makers. These relations are in turn highly explanatory of the ways people value art works and other aesthetically charged things. ${ }^{8}$

The claim is not a merely conjunctive one: not just that we delight in the aesthetics of appearances and value the skill that went into fashioning those appearances. Rather, how an artefact is seen as aesthetically delightful and/or valuable is affected by the skills and other qualities it manifests. We label this idea aesthetics as the manifestation of personal qualities, or Manifestation, or sometimes simply $M$.

$M$ is not meant as a piece of conceptual analysis. Perhaps we sometimes take a narrowly perceptual, uncontextualized pleasure in an object's appearance; there might be creatures for whom this is all the pleasure perceptual experience provides. We are happy for such pleasures to count as aesthetic and are less interested in what is essential to the aesthetic than what is important for it. Edward Craig points out that something can be deeply illuminating of a practice, without being a necessary or sufficient condition for its occurrence. ${ }^{9}$ While $M$ may not be a universal of aesthetic experience it is exemplified well beyond the Western art canon. Hand-made artefacts of all kinds may be visually indistinguishable from machine-made ones, but rarely have the same aesthetic appeal. And work in empirical psychology supports the idea that artefacts generally are understood to have an interest and value that depends as much on the performance of the maker as on the appearance or functionality of the product. ${ }^{10}$ In many languages aesthetic predicates often apply to both the activity and the result; as a commentator on Yorùbá carving and its terminology says "dídán denotes not only the beautiful "luminosity" of surface but also the sculptor's painstaking final procedure of "polishing" the object. The resulting object is the palpable index of the care that went into its manufacture". ${ }^{11}$ We might also

\footnotetext{
7 See e.g. Nehamas (2007), especially p. 94.

8 See Currie (2019). People can exercise tremendous skills and creative abilities to ends we think are not aesthetically worthwhile. If we do think that, it is likely that we take the work to manifest some failure of sensibility.

9 Craig (1991).

10 See Newman and Bloom (2011) and Cho and Schwarz (2008).

11 Doris (2005, p. 30).
} 
look to the Italian Renaissance: for Vasari, grace in a picture is the manifestation of the artist's graceful performance. ${ }^{12}$

These isolated examples prove little of course. We need detailed historical and cross-cultural studies to gauge the proper significance of $M$. As a contribution to that project we examine a practice of the distant past: Acheulean tool manufacture. We make a suggestion about what brought our distant ancestors to the point where they began, systematically and self-consciously, to experience artefacts in ways that exemplify $M$. Accordingly, Sect. 2 turns away from philosophy to that deep evolutionary past, and to why ancient stone tools are such rich sources of knowledge about the cognitive and social lives of our distant ancestors. Section 3 outlines how $M$ was exemplified in Early Stone Age culture. Section 4 gathers evidence from diverse sources to support that claim, while keeping in view the limits on our explanatory capacities; however upbeat we may be about the evidential value of stone tools, however optimistic we are about the prospects for the historical sciences, there's no disguising these speculations as established fact. ${ }^{13}$ Section 5 returns us to more philosophical territory, arguing that our narrative supports the idea that Acheulean agents were aesthetic agents; it even attempts what will seem an absurd comparison, between the Acheulean and the Quattrocento. In making it we hope to display some hidden richness in what counts as an aesthetic response to an artefact. Section 6 speculates briefly and inconclusively on how the forces of biology and culture may have helped make $M$ a regular feature of human experience.

\section{The role of Acheulean tools in cognitive archaeology}

The oldest artefacts likely to excite our aesthetic interest are the Acheulean handaxes and other stone tools, sometimes of remarkable workmanship, elegance and symmetry (Figs. 1, 2). Some go back to 1.75 million years ago (mya), though the more obviously interesting ones are said to be mostly in the period from about 0.7 myathe Late Acheulean. ${ }^{14}$ Of this industry Wynn and Gowlett say:

...the shape of an Acheulean handaxe was often "over-determined": that is, the maker gave more attention and effort to producing the shape than was nec-

\footnotetext{
12 Vasari (1568/1980). Vasari's constant theme is what the work tells of its making: works are made diligently, gracefully, the maker endowing the stone "with the attributes of living flesh", some works showing "much grace, ... made with beautiful proportion" or having "excellence of invention, grace and manner", others "so grossly made, and in such a rough style, that it is impossible to imagine worse". For commentary see Blunt (1962), especially pp. 95-100.

13 For optimism about the historical sciences see Currie (2017).

14 According to some commentators, the early Acheulean shows, in some places, a pattern of increased refinement of making through time: "Comparing the Konso handaxe assemblages of $\sim 1.75, \sim 1.6$, and $\sim 1.25 \mathrm{Ma}$, a clear increase of workmanship can be seen in edge modification and tip thinning" (Beyene et al. 2013, p. 1589).
} 
essary for basic... functionality, similar to the ornamental flourishes modern armorers add to ceremonial swords. ${ }^{15}$

It is these "ornamental flourishes" that will concern us. Over-determination in the Acheulean industry has long been noted and the idea of an aesthetic component to it is now gaining some traction in archaeological circles. ${ }^{16}$ Often this is dealt with under such headings as "perceptual bias", "peak shift", or "perceptual ambiguity", the assumption being that what aesthetics adds to the explanatory mix is the idea that functional artefacts may be reshaped by arbitrary preferences for certain perceptual forms. ${ }^{17}$ In line with Sect. 1 above, we say this is too thin an account of the aesthetic. Aesthetic elaboration has an important social function, the operation of which is no more separable from the attractions of an object's form than the aesthetic effect of a Renaissance painting is separable from one's awareness of the maker's skills and sensibilities manifested in it.

Because of their robust material constitution, we know a good deal about the making of these ancient objects. Their surfaces provide a literal blow by blow account of how they were constructed; the removal of final flakes leaves a scar on the remainder, and earlier stages in the reduction process can often be reconstructed by piecing together the on-site debitage. Flakes were removed in order then to remove further flakes and analysis suggest that makers followed a tree structure of actions: for the more complex and refined items a hierarchy of ten nested levels has been proposed. ${ }^{18}$ We are even able to reproduce the process of making through the work of modern "expert knappers" whose brain activities have been carefully recorded. Acheulean tools are an extraordinarily valuable window into aspects of the mental and physical capacities of people of several ancestor species: probably Homo ergaster and Homo heidelbergensis; possibly Homo habilis.

When it comes to cognitive archaeology, hand axes are the artefacts that keep on giving. They suggest a great deal about the social organisation of the agents who made them; as we shall see, this sheds important light on the question why these objects are sometimes over-determined, as Wynn and Gowlett put it. Peter Hiscock has reviewed the evidence for a sophisticated sensitivity to the economics of tool making even in the Oldowan technology which preceded the Acheulean: particular materials were preferred to lower quality but closer supplies, and were transported over significant distances. ${ }^{19}$ The record of caching of raw materials at this early period indicates a detailed knowledge, socially transmitted, of the material properties of lithic resources and their locations across a wide area, as well as of the related location of food sources and

\footnotetext{
${ }_{15}$ Wynn and Gowlett (2018). On the relation between shape and functionality in handaxes see Key and Lycett (2017); see also Machin et al. (2007).

${ }^{16}$ See the excellently illustrated volume First Sculpture, edited by Berlant and Wynn (2018), with commentaries by Gowlett, Wynn and others.

${ }^{17}$ See commentary by Berlant and Wynn (p. 26, 51, 73, 92, 118) and by V. S. Ramachandran (p. 69) in First Sculpture. Certainly, perceptual biases have their part to play in explaining the specific forms that human aesthetic experience takes; see Currie (2011).

${ }^{18}$ Stout (2011).

${ }^{19}$ Hiscock (2014).
} 
Fig. 1 Handaxe from Olduvai Gorge Bed II, Tanzania, about 1.4 million years old. By kind permission of Professor Thomas Wynn

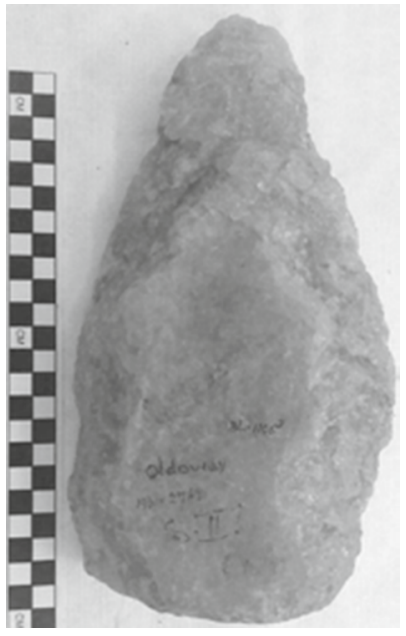

Fig. 2 Handaxe from Kathu

Pan, South Africa, about 500,000 years old. A very exceptional piece. By kind permission of Professor Thomas Wynn

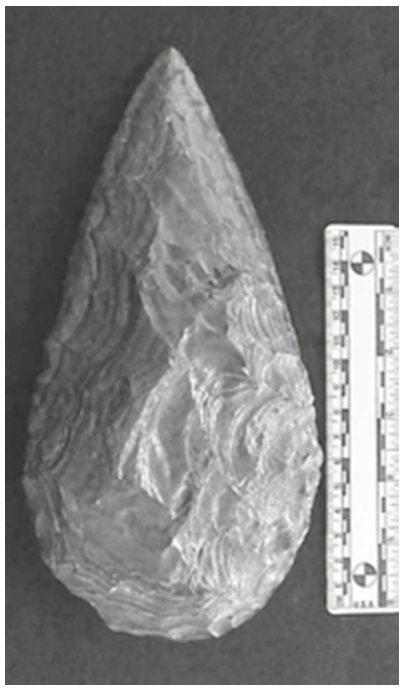

predators. Caching practices further indicate forward planning and a high degree of cooperation, with materials transported and stored ahead of use. What, then, does the process of tool manufacture suggests concerning interpersonal relations within lithic cultures? 


\section{Learning the trade}

Stone reduction in a systematic way is a complex process that requires both planning and flexible and skilful responses to a range of ways the materials can respond. ${ }^{20}$ The process is also inherently dangerous, given flying debris and an absence of medical treatment; these dangers reduce significantly with increased skill in making. Because each blow comes with the risk of both ruinous fracturing of material and injury to the maker there is pressure to make the reduction process as economical as possible, which in turn requires a plan-a "lithic narrative" as Hiscock puts ittailored to the needs of each individual piece. The return to increments of skill in lithic industries is significant, and the skills involved are complex enough to demand instruction within something that has come to be called an "apprentice system".

The idea of lithic apprenticeships is not merely that novices copied the behaviours of skilled knappers. Observation of the action of a fast-working knapper provides little useful instruction; one needs to understand how specific actions are responses both to the overall plan for the piece (the lithic narrative) and to the moment-bymoment problems thrown up by idiosyncrasies of the material and unpredicted outcomes of blows. The claim is that gaining the relevant skills in a practical time and without high risk of injury required instruction. ${ }^{21}$ Hiscock suggests that that this was given with the aid of "gestural language". ${ }^{22}$ On independent grounds, Wynn and colleagues argue that Acheulean makers possessed a kind of expertise which, in modern populations, requires possession of organised semantic categories. They conclude that "knappers had declarative/semantic labels for these concepts, either in the form of vocal words or perhaps gestures (we favour the former)". ${ }^{23}$ There is therefore some convergence towards the idea of Acheulean agents possessing at least quasi-linguistic resources to support the learning process.

The picture emerging is this. Lithic culture, through and perhaps even before the Acheulean, displays signs of complex planning, co-operation and cultural learning: assisted learning that uses cognitive processes, such as imitation and teaching, which enhance the fidelity of information transfer. ${ }^{24}$ Given the importance of the skills involved, the benefits of possessing them, and the cost to teachers in time and effort of providing them, learning opportunities may not have been freely available. Learners gravitated to those with evident skills, who could then expect to gain through returns of provisioning, co-operation and deference. Teachers competed by signalling their own (highest) levels of skill through public acts of tool production. The advantages of displaying stand-out levels of skills led to the production of artefacts which significantly exceeded the requirements of ordinary use. To help draw attention to the enhanced workmanship, these items were often made salient in

\footnotetext{
${ }^{20}$ See Stout and Khreisheh (2015) and Stout et al. (2015).

${ }^{21}$ Morgan et al. (2015).

${ }^{22}$ Hiscock ibid, p. 35. See also Sterelny (2012a). But a case against the development of complex gestural language is made in Irvine (2016).

${ }^{23}$ See Herzlinger et al. (2017).

${ }^{24}$ See Heyes (2018, p. 86).
} 
various ways: they might employ less common, hard to work and perceptually pleasing materials, display high levels of symmetry, as well sometimes as artful violations of symmetry, careful retention of a fossil or other embedded object, be of large (or notably small) size and with finely worked tips. ${ }^{25}$ Given that these were exercises in advertisement rather than practical projects, it did not matter that their displayfunction sometimes compromised or even negated their usefulness.

To the extent that acquiring these skills conferred advantages on learners, the capacity to discriminate highly skilled teachers was itself an advantage, sharpening the competition by making learners better informed about, and more rationally responsive to, the quality of the signal. As skill levels increased among makers, the power to detect the ways in which genuinely skilful making is manifested increased also. In such an environment a capacity to respond to-and especially to produceartefacts which manifest in striking ways the qualities that went into their making would be very useful. In this we see early - perhaps the earliest—signs in our lineage of an aesthetic sensibility of the kind that concerns us here. Section 6 returns to this claim. But so far we have only a story. What does the evidence say?

\section{Learning and teaching in the Acheulean: theory and evidence}

One likely objection to the story is that it depends on an exaggerated picture of the role of teaching in Early Stone Age communities. After all, current evidence from hunter-gatherer societies indicates that episodes of teaching are rare. So it is said.

Before we look at the available evidence it must be said that the potential for evidence of current teaching to support the proposal is limited; modern hunter gatherer societies are populated by modern humans and Acheulean societies were not, and there are many ways the two populations are cognitively and behaviourally distinct. On the same ground, a demonstrable or probable absence of teaching in modern hunter-gatherer societies would tell significantly against the proposal: if we don't find teaching in modern hunter-gatherer societies, what chance is there that such a cognitively demanding activity was found in communities which, despite some likely structural similarities, were populated by cognitively much more limited agents with correspondingly limited means of communication? In the light of this the best one can hope for is weak evidence for the proposal, and the avoidance of strong evidence against it. And that is what we have.

\footnotetext{
${ }^{25}$ Some authorities have suggested that there is a bias towards reporting symmetrical hand axes; James Cole (2015, p. 713) says, on the basis of an examination of 2680 bifaces from seven sites, "symmetrical bifaces do not appear to have a particularly strong presence in any assemblage and do not appear to increase as time progress" But White and Foulds (2018), while finding a degree of reporting bias, conclude that at Middle Palaeolithic sites in Britain, "the majority of handaxes are highly symmetrical or better" (p. 308). Unlike Cole, they use automated measures of symmetry rather than observer judgements. The latter method seems precarious because our intuitive standards of symmetry, derived from constant experience with machine-made items, might be quite different from those prevailing in the Acheulean.
} 
Weak, perhaps very weak, evidence would be a bad outcome from our point of view would it not? Not so bad in the circumstances. If teaching among modern hunter-gatherers was the only reason we had for believing in teaching in the Acheulean, the hypothesis would not be very credible. But we do have another reason for believing this: the intrinsic difficulty of acquiring the complex lithic skills described above without teaching. In developing their theoretical model of the evolution of teaching Fogarty et al. say that "cumulative cultural evolution allows complex, high fitness traits that no individual could acquire on his or her own or through inadvertent social learning, ranging from ancestral lithic technology, tools and weaponry through to contemporary technology, to be present and available to teach in human populations." 26 Tehrani and Riede say that "Even armed with a highly sophisticated set of imitative abilities, it is difficult to imagine how a novice could... achieve the delicately calibrated balance between precision and power exercised by a master stone knapper, just by repeated observation." They add that "it seems highly probable that teaching has been an important mechanism of material culture transmission since at least the Lower Palaeolithic, when the first complex lithic forms emerged."27

For all this, it would be of concern if it turned out that in the only societies we can now meaningfully compare with the Acheulean there is no evidence of teaching. In disputing this latter claim, as we shall, our hope is not that evidence of teaching in modern hunter-gatherer societies will raise the probability of the hypothesis very high, but rather that, by protecting it from a substantially undermining counter-argument, it will prevent it from falling very low.

Our story's potential for confirmation is limited in two other ways. First of all, much of the current evidence of teaching in hunter-gatherer societies concerns processes of child-learning. Despite denials from some investigators, there is evidence of child-teaching in hunter-gatherer societies, once we abandon the idea that this requires an institutionalised setting. ${ }^{28}$ However, evidence of this kind is problematic from our point of view for two reasons: (i) it is unlikely that very young people in the Acheulean would have been taught the skills of lithic tool manufacture, given the strength and dexterity required, and (ii) inferences concerning children from modern hunter-gatherer societies to those of the Acheulean are particularly precarious on the assumption that the length of childhood has increased dramatically between these times. For our purposes, better evidence would be of teaching in adolescence and early adulthood, especially given that, on the present hypothesis, learners played an active part in choosing teachers.

\footnotetext{
${ }^{26}$ Fogarty et al. (2011, p. 2767).

${ }^{27}$ Tehrani and Riede (2008, p. 318). Indeed there is evidence of copying errors in the archaeological record, adding support to the idea that the reproduction of tool-making techniques was intrinsically difficult; see Lycett et al. (2016) and Shipton et al. (2019).

${ }^{28}$ Evidence reviewed by Csibra and Gergely (2011) comes from the Aka in West Africa, where "[p]eople reported that they had learnt most $(80 \%)$ of their skills from their parents, often by teaching" [citing Hewlett and Cavalli-Sforza (1986)] and the Kpelle in Liberia: "knowledgeable adults teach their children about medicines (p. 68) and board games (p. 116), give advice about making traps (p. 146), guide children's hands when learning how to weave a bag (pp. 151-152) and demonstrate how to make a hammock (p. 154)" [citing Lancy (1996)].
} 
Secondly, a good deal of evidence of teaching beyond childhood is related to the inculcation of what are called "Cultural Values and Kinship" and "Religious Beliefs and Practices". ${ }^{29}$ Evidence of teaching of this kind, which often involves storytelling, would not be good evidence of the kind of close, practice-based teaching required for passing on lithic skills. ${ }^{30}$ While some things relevant to lithic manufacture such as resource location might be conveyed in narrative form, lithic skills are, as emphasised above, highly dependent on competence with the idiosyncrasy of materials. ${ }^{31}$ Nor can we assume that Acheulean agents had a language that would bear the weight of story-telling.

Our focus is on skills-based teaching of maturing and mature agents in huntergatherer societies. Particularly relevant is the inculcation of hunting skills which are complex, and not taught until adolescence. For this there certainly is evidence. Dira and Hewlett studied hunting among the Chabu people and found that verbal instruction was the most common form for teaching these skills; also, Chabu adolescents were able to choose between teachers. ${ }^{32}$ More generally, Boyette and Hewlett report that direct instruction is used most often in the domains of complex ecological knowledge or subsistence skills, of which stone tool making is one. ${ }^{33}$ On a more personal note Bonnie Hewlett recounts her experience of learning basket weaving from women of the Aka people. It involved demonstration, instruction and correction over 3 weeks for many hours at a time and apparently did not seem odd or difficult to those supplying it. ${ }^{34}$

The best evidence for our story would be from the modern transmission of lithic skills. There are few contemporary communities where stone tool manufacture continues but detailed ethnographic evidence from a village in what is now Papua Province documents an apprenticeship system that can last 10 years aimed at producing the long and slender ads heads used in this agricultural (rather than hunter-gatherer) community. Traditionally, apprenticeship here began around the age of 12-13. With the availability of industrially made tools demand has declined and interest in the skill seems now to be connected with the perceived value of tradition; apprentices are more often in their twenties. ${ }^{35}$

\footnotetext{
${ }^{29}$ See Garfield et al. (2016).

${ }^{30}$ Cultural and religious teaching often takes the form of story-narration; see Scalise Sugiyama (2017).

31 See Stout et al. (2002): "Individuals interviewed indicated that finding high-quality material is one of the most difficult and important aspects of adze production" (p. 696); "Craftsmen who happen to be in the immediate area gather to discuss the merits of the selected boulder, commenting on the size and uniformity of the grain, the danger of internal flaws (ismar), and the presence of black (bataya) or white (boladiatenga, "deepskin belt") mineral bands.... Although they realize that these bands often represent points of weakness in the rock, the adze makers prize them for their aesthetic value" (p. 697).

32 Dira and Hewlett (2016).

33 Boyette and Hewlett (2017).

34 Hewlett (2013).

35 "It is quite common, for example, for one man to make suggestions to another about where to attempt the next flake removal or to comment on the quality of the material being worked. Similarly, a worker who is experiencing difficulties may ask another to try his hand at the task. Such interaction occurs between peers but is most frequent between experts and apprentices" (Stout et al. 2002, p. 703).
} 
The vast temporal distance between the Acheulean and now makes retrodiction hazardous. But there is, finally, some evidence of teaching in at least the Upper Palaeolithic. Using analysis of the operator chain at Magdalenian sites, Pigeot claims to have reconstructed evidence for an apprenticeship system. ${ }^{36}$ Similar inferences have been made concerning late Palaeolithic sites such as Trollesgave, eastern Denmark where Fischer argues for a 'school of flintknapping. ${ }^{37}$ Kim Sterelny cites a study by Linda Grimm according to which "some cores show evidence of being largely made by inexpert knappers, but from blanks provided by experts, and with occasional expert intervention". 38

After this presentation of theory and evidence we turn to an interpretive question that needs a good deal of philosophical structuring: to what extent is the Acheulean an aesthetic culture?

\section{Aesthetic sensibility}

Does the story so far support the attribution of aesthetic sensitivity to Acheulean agents? Aesthetic sensitivity comes in degrees and we should avoid a very demanding conception of what such sensitivity amounts to, or one keyed to the idiosyncrasies of art in the twenty-first century. We should not require Acheulean agents to have a concept of the aesthetic, just as we don't need to attribute a concept of sex to agents who show an interest in sexual partners. ${ }^{39}$ We should not require that Acheulean agents have some uniquely "aesthetic" experience: attempts to specify such a thing for humans has been one of the failures of modern aesthetics. We can assume instead that aesthetic experience was as heterogeneous for them as it seems to be for us. We should also not require that Acheulean agents engaged in conscious reasoning about the aesthetic qualities of their artefacts; few of us do that. All we need say is that these agents were apt to take pleasure in the sensory qualities these objects presented (primarily visual but possibly tactile as well), where that pleasure is modulated by awareness of the ways those sensory qualities manifest the skills exercised in their production. Again, this modulation need not function by way of reasoning; we need only attribute to these agents a primitive capacity to "see" skilful making in these objects just as we "see" personal qualities, from simple fearfulness to resoluteness, in the demeanours and actions of our fellows. Our scare quotes recall what we previously granted: that neither of these cases need be literally a matter of seeing; the narrow theory of perceptual content may be true. But if we do not literally see fearfulness or dignity we often do not reason our way to them; we find ourselves recognising the agent as fearful in a way that makes talk of seeing these things very natural. We sometimes recognise, in the same visually guided and mandatory way,

\footnotetext{
36 Pigeot (1990).

37 Fischer (1989). Evidence from Upper Palaeolithic sites is summarised in Tehrani and Riede (2008).

38 Sterelny (2012b, p. 42), citing Grimm (2000).

39 Lopes (2007) argues that there are artistic communities with no concept of art; not that we are arguing that the Acheulean was an artistic community_-see this section further on.
} 
the skilfulness manifested in an artefact, though it may take experience and background knowledge to get us to that point. A pleasure taken in form-as-indicative-ofskilful-making is all we require to support the very modest levels of aesthetic sensibility we are attributing to Acheulean subjects. Later in this section we will suggest an enrichment to this minimalist account of the aesthetic: one which is certainly present in historical times and may have been present in the Acheulean.

An objection to the minimal aesthetic is that Acheulean agents regarded the appearances of lithic artefacts instrumentally, that is, as useful indicators of skills, whereas aesthetically sensitive agents derive satisfaction from the appearances of things "for themselves", as we say. But what is enjoyed "for itself" may also have substantial instrumental value, where that instrumental value is a precondition of any attribution of "final" value. Christine Korsgaard says

A mink coat can be valued the way we value things for their own sakes: a person might put it on a list of the things he always wanted, or aspire to have some day, right alongside adventure, travel, or peace of mind. Yet it is also odd to say it is valued simply for its own sake. A coat is essentially instrumental: were it not for the ways in which human beings respond to cold, we would not care about them or ever think about them.... Mink coats... are things that human beings might choose partly for their own sakes under the condition of their instrumentality: that is, given the role such things play in our lives. ${ }^{40}$

In the same way we may concede that hand axes are essentially instrumental and that their significance for Acheulean agents depends on the nexus of transactions they facilitate, be they episodes of meat-extraction or of skill-signalling. Yet, under these "conditions of instrumentality" they, or their appearances, may be admired "for their own sakes".

In the same place Korsgaard makes a related and important point, though one which subsequent commentators have sought to amend. ${ }^{41}$ For our purposes we need say only the following. We may think of something as having value merely as an instrument that helps us achieve something else which is (let's suppose) of final value. But if we think of it as having final value there is a tendency to assume that its value must be intrinsic, or "in itself"- - value that does not depend on any other thing. Contrapositively, if we think a thing's value does depend on something elseit has, we may say, extrinsic value - then we think of its value as instrumental. In line with this way of thinking one might hear what was said at the beginning of this paper and respond: "So the focus of our aesthetic interests, the thing we are attributing aesthetic value to, is not really the artefact but the agent who made it; it is the agent's qualities that we really care about. That is what is intrinsically valuable; the artefact is valuable in so far as it makes those qualities manifest".

This line of thinking is mistaken. The value a painting has may depend (in part) on it bearing the manifestation relation to its maker; to say that is to agree that the value the painting has is extrinsic. It is not to say that the painting has value merely

${ }^{40}$ Korsgaard (1983, p. 185).

${ }^{41}$ See e.g. Langton (2007) and Dancy (2004), Chapter 9. 
as a means to the identification of the maker and their qualities. Likewise, one may value a wedding ring because of its connection with a wedding, but it does not follow that one values it only instrumentally. ${ }^{42}$ Nicholas Humphrey, writing about aesthetics' evolutionary past, rightly says that

...we value the work of art only when we see the human hand behind it. We marvel at the cave paintings at Lascaux, for example, only because we believe they were made by artists. If it were to turn out these images had been created by accidental water stains, they' $\mathrm{d}$ become merely quaint. ${ }^{43}$

He also says "We may seem to love beautiful things as if it were indeed the thing of beauty in itself that counts for us. But our feeling about the thing is always a proxy for our feeling about some idealised person in the background." This mischaracterises our valuing of beautiful things: we do attribute to them final value. The fact that our valuing depends on their relations to a maker should not tempt us to deny this.

In the light of this there is, we suggest, some continuity between the Acheulean and more obviously aesthetic cultures like the Quattrocento, with their hyper-refined standards. High aesthetic cultures have not put aside practical interests; aesthetic production in fifteenth century Italy was strongly governed by the social ambitions of patrons, who controlled the subject, appearance and materials of the work. Aesthetic production was not then driven by the need to co-ordinate learners and teachers, since patrons did not generally seek artistic skills. But patrons, then as now, were intensely sensitive to the ways in which the pictures that interested them manifested skills of making. As Baxandall says, "[the patron] was aware that the good picture embodied skill and he was frequently assured that it was the part of the cultivated beholder to make discriminations about that skill". ${ }^{44}$ Baxandall's focus is securely on the picture as site of transaction between maker and viewer, emphasising the skills necessary properly to discriminate and assess the skills embodied in the picture, and how the exercise of these embodied skills contributes to the pleasure that pictures afford: "If a painting gives us opportunity for exercising a valued skill and rewards our virtuosity with a sense of worthwhile insights into that painting's organisation, we tend to enjoy it". This suggests a further step, one that Baxandall does not explicitly make: to bring within the domain of the aesthetic one's enjoyment of the skills and sensibilities one brings to the task of appreciating those (different) skills and sensibilities manifested in the work. Kendall Walton, in the process of outlining a theory of aesthetic pleasure, is tempted by this idea: "As a first stab, let's define aesthetic pleasure as pleasure which has, as a component, pleasure taken in one's admiration or positive evaluation of something". ${ }^{45}$ But he draws back from this formulation:

\footnotetext{
${ }^{42}$ The example is due to Langton (2007) who at this point offers an emendation to Korsgaard; we can ignore this.

${ }^{43}$ Beauty's child, at http://www.humphrey.org.uk/papers/2010Beauty'sChild.pdf. This otherwise unpublished essay is impressive and deserves to be read more widely.

${ }^{44}$ Baxandall (1988, p. 34).

${ }^{45}$ Walton (1993, p. 505).
} 
A person might take pleasure of a self-congratulatory sort in admiring something; one might pat oneself on the back, with delight, for one's sophisticated and subtle taste in recognizing the thing's merit. This pleasure would seem not to be aesthetic. ${ }^{46}$

We are unsure why a self-congratulatory pleasure cannot be aesthetic when othercongratulatory pleasures apparently can be. Calling this pleasure "self-congratulatory" suggests that it is indulgent and perhaps self-deceptive. No doubt it can be; it might on the other hand be entirely realistic. And an appreciation of a picture's own qualities can be indulgent; you fail to see what is wrong with its sentimentality. It may even be self-deceptive, having you assign it qualities which you in some sense know it lacks. In such a case we would have a defective aesthetic response, but still an aesthetic one. The same applies, we say, for the self-congratulatory case. Without claiming that pleasure taken in the exercise of one's own discriminatory powers is essential to any experience that could be called aesthetic, it is surely a frequently important part of what motivates us to struggle, as we sometimes do, to understand works with qualities which are difficult to discern, and which may require considerable training and experience to reveal. ${ }^{47} \mathrm{We}$ do not, and perhaps cannot, know whether Acheulean agents experienced this kind of reflexive pleasure-pleasure taken in one's own discernment of the qualities of things. But the outline we have given of aesthetic transactions in the Acheulean certainly makes room for this. Prospective apprentices needed to see-to be keen to learn to see-the qualities manifested in the products of skilled makers. ${ }^{48}$

Where does value come into this? Among aestheticians it's widely held that aesthetic experience is essentially normative; that it is "definitive of pleasure in beauty that it licenses judgments that make claim to correctness". ${ }^{49}$ One might suspect that Acheulean agents lacked such a normative conception. However, a recent empirical study across 19 countries in Asia, Europe, and the Americas failed to find much evidence of this normative stance among contemporary non-aestheticians; in all regions the least favoured response (7\% of 2392 responses overall) to a situation where one finds an object beautiful and the other does not was "One of you is correct while the other is not". ${ }^{50}$ Level of education, exposure to philosophy, and reflective cognitive style were positively correlated with the most popular response (52\%): "Neither

\footnotetext{
46 Ibid, pp. 505-506, our emphasis; see also his discussion at pp. 507-508.

47 It may also account for what has been called the vice of snobbery in aesthetic appreciation (Kieran 2010), and hence be a reason why aesthetic appreciation is rather fragile.

48 On much we are in agreement with Walton: "An appreciator's enjoyable admiration, usually if not always, involves not only recognizing a thing's value-recognizing the marvelous job it does of opening our eyes to important truths, for instance, or how wonderfully suited it is for providing safe and efficient transportation; one's admiration also involves recognizing the creator's accomplishment, the talent and skill a person demonstrated by producing something with this value" (Walton 1993, p. 506).

49 James Shelley, Aesthetic Judgment, Stanford Encyclopedia of Philosophy, https://plato.stanford.edu/ entries/aesthetic-judgment/\#Norm.

50 Cova et al. (2019): The highest proportion of objectivist responses was found in South and Southeast Asian respondents (22.0\%).
} 
is correct. It makes no sense to talk about correctness in this situation." ${ }^{51}$ If these results are robust it will be hard to argue that folk-aesthetics is decisively normative. On the other hand, it would be interesting to see how answers would be distributed if the question specifically concerned disagreement about what skills and abilities are evident in the picture, musical passage, or whatever was in question. Our guess is that subjects would in this case be drawn towards some form of objectivism in their responses. Without supposing that Acheulean agents reflected much or at all on this, our story of learners and teachers in the Early Stone Age suggests that their behaviour would betray a sensitivity to the possibility of being wrong about what skills were manifested on a particular occasion; it is important to our story, after all, that being right on this subject gave Acheulean agents an advantage in learning.

While more needs to be said on this complex topic we suggest this as a temporary stopping place: if there is a core of objectivity in people's pre-theoretical approach to aesthetic objectivity, it is to be found in the ways we judge aesthetic success in terms of the effective deployment of skills.

In this section we compared the Acheulean not merely to an aesthetic culture but to one which is paradigmatically artistic: the Quattrocento. That was an artistic culture within which aesthetic values were deeply embedded, but the two conditions are separable; the rise of anti-aesthetic art in our own time shows that in one direction, and it has always been recognised that many artefacts that give aesthetic pleasure-well-designed computers, Korsgaard's "gorgeously enameled frying pans"do not count as art. ${ }^{52}$ The relations between art and the aesthetic are complex and contested: we are not claiming that the Acheulean was an artistic culture, and we do not know how one would go about deciding whether it was.

\section{Evolutionary speculations ${ }^{53}$}

The Acheulean occupied perhaps a million and a half years of hominin evolution. How does our story of the emergence of aesthetic sensibility connect with the mechanisms of evolution? These days we have a rich menu of explanatory options, from the postulation of a genetically determined instinct at one end, through theories that propose mechanisms of gene-culture interaction, to the cultural constructivism of Heyes, for whom such distinctively human adaptations as imitation, mentalizing and language (hereafter "the triad") arose and stabilised in the culturally determined way that is generally agreed for reading/writing. ${ }^{54}$ Along with most others we reject the genetic determinism option. It is harder to be confident as between remaining alternatives, and in this section our aims are very modest; we do no more than (a) clarify

\footnotetext{
51 Cova et al. (2019): A third response "Both of you are correct" was favoured by $41 \%$.

52 Korsgaard (1983, p. 185). For the aesthetics of non-art objects and the tendency to see art objects as central cases of the aesthetic, see Saito (2007, pp. 13-18).

53 We are grateful to the editors of this special issue for comments which led to substantial changes in this section.

${ }^{54}$ See Heyes (2018, pp. 148-151).
} 
how the debate between alternatives is best understood by someone interested in the question immediately above; (b) point to a domain of inquiry where relevant evidence may be found; (c) emphasise the weakness of the currently available evidence.

After genetic determinism, next along the shelf of options is appeal to some form of gene-culture interaction, with genetic assimilation a currently popular version. Genetic assimilation - a relation of the Baldwin effect-is appealed to by Dor, Ginsberg and Jablonka in discussing an aspect of Acheulean culture:

Genetic assimilation... occurs when a developmentally-induced or learned response becomes less dependent on environmental induction or on learning. For example, if a million years ago, during the teaching of Acheulean toolmaking, more efficient imitation-learning was beneficial, selection for better imitators could lead to the genetic assimilation of genes that facilitate vocal and motor imitation. ${ }^{55}$

Their suggestion is that the complex demands of Acheulean tool making required imitation-learning, and so favoured a degree of genetic control "that allowed individuals to put less effort into their learning, as long as it did not jeopardize too much other learning capacities" (519). We have argued that the complexity of Acheulean tools made imitation on its own an ineffective means of skill-transfer. ${ }^{56}$ Acquiring expertise in this area required a suite of capacities, including imitation but also the ability to discriminate between more and less skilful productions in others. The thought then naturally occurs that this too was subject to genetic assimilation.

This line of argument is rejected by Heyes, who claims that even those capacities most likely to be seen as under at least partly genetic control-including our triad-are in fact the product of cultural change, just as reading and writing are generally thought to be. Heyes' leading argument (she has others) is that "distinctively human cognitive mechanisms are tracking targets that move too fast for genetic evolution". 57 To us, this suggests a too high-level specification of the cognitive mechanisms in question. As Roige and Carruthers (2019) put it "Although what one needs to learn from one's culture is continually shifting, copying the prestigious remains a good strategy; although the actions that need to be imitated change, a system that fast-maps vision and audition to action remains useful". ${ }^{58}$ But we can't here adjudicate this complex issue with its many strands of argument; instead we take a step back and note this dialectical point: it is generally agreed that reading/writing is a purely cultural phenomenon, so one way to think about the evolution of skills-based aesthetic sensibility is to decide whether it is substantially similar to reading/writing and substantially dissimilar from the triad. If it is, there is a prima facie case for seeing that sensibility as wholly cultural; if that sensibility looks significantly like capacities in the triad and unlike reading/writing progress will then depend on a

\footnotetext{
55 Dor et al. (2019, p. 524). They go on to note that "genetic assimilation is almost always partial, leading to quicker and more efficient context-sensitive responses rather than to stimulus-independent “instincts" (p. 525). David Papineau uses the term "genetic takeover"; see his (2005) excellent The Cultural Origins of Cognitive Adaptations.

56 See above, text to notes 28 and 29.

57 Heyes (2018, p. 208).

58 Roige and Carruthers (2019, p. 541).
} 
decision about whether, despite appearances, capacities in the triad are really of the same kind as reading/writing. ${ }^{59}$

This is another dispute we cannot settle here. A useful first step might be to ask whether skills-based appreciation shows a developmental trajectory that is quick and reliable, something generally regarded as distinctive of capacities in the triad. As far as we can see, the question has never been raised in the developmental literature and even indirect evidence is thin on the ground. An obvious place to look is studies of children's responses to art and we will note one study of this kind. Nissel, HawleyDolan \& Winner examined the responses of children to abstract pictures made by two groups: firstly, famous artists such as Hofmann, Frankenthaler and Rothko, and secondly, children and animals. They presented 4-7- and 8-10-year olds with paired images, and asked which the children preferred and which was better. ${ }^{60}$ An earlier study (Hawley-Dolan and Winner 2011) presented pictures by artists paired with pictures by children or animals to adults with no background in art; they were asked which they liked more and which were of better quality. Some pairs were unlabelled while others had either true or reversed labels (artist and child, monkey, elephant). In all cases, adults preferred and judged as better the works by the artists. Interestingly, their justifications for claims of quality significantly involved reference to abilities, citing for example a degree of intentionality and successful planning. ${ }^{61}$

The children in the 2014 experiment showed a much less consistent pattern for true and reversed labelling; focusing only on the unlabelled condition, for younger children, $40 \%$ of preferred pictures were by artists, while $45 \%$ of those picked for quality were by artists; the comparable result for older children was $40 \%$ and $53 \%$ while for adults it was $59 \%$ and $72 \%$. Nissel et al. conclude that "it appears as if [concerning judgements of quality] the 8- to 10-year-olds' responses are on a trajectory in between those of the 4- to 7-year-olds and the adults" (p. 24). But this trajectory looks slow, with the oldest children (10 years) still judging work by artists to be of better quality only about half the time; little obvious reason to postulate a biological force at work additional to enculturation. ${ }^{62}$ Also, the details of the study do not indicate to what extent children's judgements of quality were influenced by considerations of skill; no one doubts, we hope, that the ones by artists were in fact the more skilfully executed, but we would be presuming the truth of our own thesis if we concluded that judgements of aesthetic quality, as revealed by these experiments, were driven by sensitivity to skill. ${ }^{63}$

\footnotetext{
59 Even Heyes (2019, p. 557) grants that appearances are against the "same kind" hypothesis: "Even when one studies the evidence of late development and everyday instruction, the intuition remains (I still have it) that, while learning to read print is a laborious business, learning to imitate, talk and read minds is like falling off a log.".

60 Nissel et al. (2016).

61 Hawley-Dolan and Winner (2011).

62 The 10-year old group was small (8) and the proportion of their choices of artist-works as showing better quality (48\%) was below that for two year groups immediately below. Here are the proportions for that same judgement by year group from age 4 to age 10: 4:35\%, 5:44\%, 6:46\%, 7:50\%, 8:55\%, 9:53\%, $10: 48 \%$. Even if the figure for the 10-year old group is an underestimation progress looks slow.

63 Though children "sometimes justified their choices [in favour of a picture by a child or animal] by crediting the effort the child or animal had made (e.g., 'it's really good for an elephant')" (p. 18, see also p. 26).
} 
At this stage we believe that very little can be said with confidence about the mechanisms that replicate a skills-based aesthetic sensitivity across the generations.

\section{Conclusion}

We have suggested that there are very ancient signs of what is also a very modern sensibility: delight in the appearances of artefacts which display, through their appearances, the personal qualities that contributed to their having those very appearances. Drawing on recent archaeological work we offered an account of the influence on this process of what we might call the lithic niche: those alterations to the environment of Acheulean agents caused by their use of stone tools-alterations which radically reshaped social relations and created a need for the transmission of complex skills. We argued that this gives us grounds for thinking that the Acheulean was an aesthetic culture, though not, for all we know, an artistic one.

Funding Funding for Xuanqi Zhu was provided by China Scholarship Council (Grant No. 201708060229).

Open Access This article is distributed under the terms of the Creative Commons Attribution 4.0 International License (http://creativecommons.org/licenses/by/4.0/), which permits unrestricted use, distribution, and reproduction in any medium, provided you give appropriate credit to the original author(s) and the source, provide a link to the Creative Commons license, and indicate if changes were made.

\section{References}

Alberti, L. B. (1435/1970). On painting (John R. Spencer, Trans.). New Haven: Yale University Press.

Baxandall, M. (1988). Painting and experience in fifteenth century Italy: A primer in the social history of pictorial style. Oxford: Oxford University Press.

Berlant, T., \& Wynn, T. (2018). First sculpture: Handaxe to figure stone. Dallas, TX: Nasher Scupture Center.

Beyene, Y., Katoh, S., WoldeGabriel, G., Hart, W. K., Uto, K., Sudo, M., et al. (2013). The characteristics and chronology of the earliest Acheulean at Konso, Ethiopia. Proceedings of the National Academy of Sciences, 110(5), 1584-1591.

Blunt, A. (1962). Artistic theory in Italy, 1450-1600. Oxford: Oxford University Press.

Boyette, A. H., \& Hewlett, B. S. (2017). Teaching in hunter-gatherers. Review of Philosophy and Psychology, 9(4), 771-797.

Cho, H., \& Schwarz, N. (2008). Of great art and untalented artists: Effort information and the flexible construction of judgmental heuristics. Journal of Consumer Psychology, 18(3), 205-211.

Cole, J. (2015). Examining the presence of symmetry within Acheulean handaxes: A case study in the British Palaeolithic. Cambridge Archaeological Journal, 25(4), 713-732.

Coleman, E. B. (2004). Appreciating "traditional" Aboriginal painting aesthetically. The Journal of Aesthetics and Art Criticism, 62(3), 235-247.

Cova, F., et al. (2019). De Pulchritudine non est Disputandum? A cross-cultural investigation of the alleged intersubjective validity of aesthetic judgment. Mind and Language, 34(3), 317-338.

Craig, E. (1991). Knowledge and the state of nature: An essay in conceptual synthesis. Oxford: Clarendon Press.

Csibra, G., \& Gergely, G. (2011). Natural pedagogy as evolutionary adaptation. Philosophical Transactions of the Royal Society B: Biological Sciences, 366(1567), 1149-1157.

Currie, A. (2017). Rock, bone, and ruin: An optimist's guide to the historical sciences. Cambridge: MIT Press. 
Currie, G. (2011). The master of the Masek Beds: Handaxes, art, and the minds of early humans. In E. Schellekens \& P. Goldie (Eds.), The aesthetic mind: Philosophy and psychology (pp. 9-31). Oxford: Oxford University Press.

Currie, G. (2012). Art and the anthropologists. In A. Shimamura \& S. Palmer (Eds.), Aesthetic science: Connecting minds, brains, and experience (pp. 107-128). New York: Oxford University Press.

Currie, G. (2019). Pictures and their surfaces. In J. Pelletier \& A. Voltolini (Eds.), The pleasure of pictures: Pictorial experience and aesthetic appreciation (pp. 249-269). Abingdon: Routledge.

Dancy, J. (2004). Ethics without principles. Oxford: Oxford University Press.

Davies, S. (2006). Aesthetic judgements, artworks and functional beauty. The Philosophical Quarterly, 56, 224-241.

Dira, S. J., \& Hewlett, B. S. (2016). Learning to spear hunt among Ethiopian Chabu adolescent hunter-gatherers. In H. Terashima \& B. S. Hewlett (Eds.), Social learning and innovation in contemporary huntergatherers (pp. 71-81). Tokyo: Springer.

Dor, D., Ginsburg, S., \& Jablonka, E. (2019). The evolution of cultural gadgets. Mind and Language, 34(4), $518-529$.

Doris, D. T. (2005). Symptoms and strangeness in Yoruba anti-aesthetics. African Arts, 38(4), $24-31$.

Dutton, D. (1979). Artistic crimes: The problem of forgery in the arts. British Journal of Aesthetics, $19,308$.

Fischer, A. (1989). A late Palaeolithic 'School' of Flint-knapping at Trollesgave, Denmark. Results from refitting. Acta Archaeologica, 60, 33-49.

Fogarty, L., Strimling, P., \& Laland, K. N. (2011). The evolution of teaching. Evolution: International Journal of Organic Evolution, 65(10), 2760-2770.

Garfield, Z. H., Garfield, M. J., \& Hewlett, B. S. (2016). A cross-cultural analysis of hunter-gatherer social learning. In H. Terashima \& B. S. Hewlett (Eds.), Social learning and innovation in contemporary hunter-gatherers (pp. 19-34). Tokyo: Springer.

Grimm, L. (2000). Apprentice Flintknapping: Relating material culture and social practice in the Upper Paleolithic. In J. Safaer Derevenski (Ed.), Children and material culture (pp. 53-71). London: Routledge.

Hawley-Dolan, A., \& Winner, E. (2011). Seeing the mind behind the art: People can distinguish abstract expressionist paintings from highly similar paintings by children, chimps, monkeys, and elephants. Psychological Science, 22(4), 435-441.

Helton, G. (2016). Recent issues in high-level perception. Philosophy Compass, 11(12), 851-862.

Herzlinger, G., Wynn, T., \& Goren-Inbar, N. (2017). Expert cognition in the production sequence of Acheulian cleavers at Gesher Benot Ya'aqov, Israel: A lithic and cognitive analysis. PLoS ONE, 12(11), e0188337.

Hewlett, B. L. (2013). Listen, here is a story: Ethnographic life narratives from Aka and Ngandu women of the Congo Basin. Oxford: Oxford University Press.

Hewlett, B. S., \& Cavalli-Sforza, L. L. (1986). Cultural transmission among Aka pygmies. American Anthropologist, 88(4), 922-934.

Heyes, C. (2018). Cognitive gadgets: The cultural evolution of thinking. Cambridge: Harvard University Press.

Heyes, C. (2019). Testing cognitive gadgets. Mind and Language, 34(4), 551-559.

Hiscock, P. (2014). Learning in lithic landscapes: A reconsideration of the hominid "toolmaking" niche. Biological Theory, 9(1), 27-41.

Irvine, E. (2016). Method and evidence: Gesture and iconicity in the evolution of language. Mind and Language, 31(2), 221-247.

Key, A. J., \& Lycett, S. J. (2017). Influence of handaxe size and shape on cutting efficiency: A largescale experiment and morphometric analysis. Journal of Archaeological Method and Theory, 24(2), 514-541.

Kieran, M. (2010). The vice of snobbery: Aesthetic knowledge, justification and virtue in art appreciation. Philosophical Quarterly, 60, 243-263.

Korsgaard, C. M. (1983). Two distinctions in goodness. Philosophical Review, 92(2), 169-195.

Lancy, D. F. (1996). Playing on the mother-ground: Cultural routines for children's development. New York: Guilford Press.

Langton, R. (2007). Objective and unconditioned value. Philosophical Review, 116(2), 157-185.

Lopes, D. M. (2007). Art without 'art'. British Journal of Aesthetics, 47(1), 1-15.

Lycett, S. J., Schillinger, K., Eren, M. I., von Cramon-Taubadel, N., \& Mesoudi, A. (2016). Factors affecting Acheulean handaxe variation: Experimental insights, microevolutionary processes, and macroevolutionary outcomes. Quaternary International, 411, 386-401. 
Machin, A. J., Hosfield, R. T., \& Mithen, S. J. (2007). Why are some handaxes symmetrical? Testing the influence of handaxe morphology on butchery effectiveness. Journal of Archaeological Science, 34(6), 883-893.

Morgan, T. J., Uomini, N. T., Rendell, L. E., Chouinard-Thuly, L., Street, S. E., Lewis, H. M., et al. (2015). Experimental evidence for the co-evolution of hominin tool-making teaching and language. Nature communications, 6, 6029 .

Nehamas, A. (2007). Only a promise of happiness: The place of beauty in a world of art. Princeton: Princeton University Press.

Newman, G. E., \& Bloom, P. (2011). Art and authenticity: The importance of originals in judgments of value. Journal of Experimental Psychology: General, 141(3), 558.

Nissel, J., Hawley-Dolan, A., \& Winner, E. (2016). Can young children distinguish abstract expressionist art from superficially similar works by preschoolers and animals? Journal of Cognition and Development, $17(1), 18-29$.

Papineau, D. (2005). The cultural origins of cognitive adaptations. Royal Institute of Philosophy Supplements, 56, 291-324.

Pigeot, N. (1990). Technical and social actors. Flintknapping specialists and apprentices at Magdalenian Etiolles. Archaeological Review from Cambridge, 9(1), 126-141.

Roige, A., \& Carruthers, P. (2019). Cognitive instincts versus cognitive gadgets: A fallacy. Mind and Language, 34(4), 540-550.

Rose, S. (2017). The fear of aesthetics in art and literary theory. New Literary History, 48(2), 223-244.

Saito, Y. (2007). Everyday aesthetics. Oxford: Oxford University Press.

Scalise Sugiyama, M. (2017). Oral storytelling as evidence of pedagogy in forager societies. Frontiers in Psychology, 8, 471.

Shipton, C., Clarkson, C., \& Cobden, R. (2019). Were Acheulean bifaces deliberately made symmetrical? Archaeological and experimental evidence. Cambridge Archaeological Journal, 29(1), 65-79.

Sibley, F. (2001). Approach to aesthetics: Collected papers on philosophical aesthetics. Oxford: Clarendon Press.

Sterelny, K. (2012a). Language, gesture, skill: The co-evolutionary foundations of language. Philosophical Transactions of the Royal Society B: Biological Sciences, 367(1599), 2141-2151.

Sterelny, K. (2012b). The evolved apprentice: How evolution made humans unique. Cambridge: MIT Press.

Stout, D. (2011). Stone toolmaking and the evolution of human culture and cognition. Philosophical Transactions of the Royal Society B: Biological Sciences, 366(1567), 1050-1059.

Stout, D., Bril, B., Roux, V., DeBeaune, S., Gowlett, J. A. J., Keller, C., et al. (2002). Skill and cognition in stone tool production: An ethnographic case study from Irian Jaya. Current Anthropology, 43(5), 693-722.

Stout, D., Hecht, E., Khreisheh, N., Bradley, B., \& Chaminade, T. (2015). Cognitive demands of Lower Paleolithic toolmaking. PLoS ONE, 10(4), e0121804.

Stout, D., \& Khreisheh, N. (2015). Skill learning and human brain evolution: An experimental approach. Cambridge Archaeological Journal, 25(4), 867-875.

Tehrani, J. J., \& Riede, F. (2008). Towards an archaeology of pedagogy: Learning, teaching and the generation of material culture traditions. World Archaeology, 40(3), 316-331.

Vasari, G. (1568/1980). The lives of the painters, sculptors \& architects. Everyman Library. J.M.Dent \& Sons Ltd.

Walton, K. L. (1970). Categories of art. Philosophical Review, 79(3), 334-367.

Walton, K. L. (1993). How marvelous! Toward a theory of aesthetic value. The Journal of Aesthetics and Art Criticism, 51(3), 499-510.

White, M., \& Foulds, F. (2018). Symmetry is its own reward: On the character and significance of Acheulean handaxe symmetry in the Middle Pleistocene. Antiquity, 92(362), 304-319.

Wynn, T., \& Gowlett, J. (2018). The handaxe reconsidered. Evolutionary Anthropology: Issues, News, and Reviews, 27(1), 21-29.

Publisher's Note Springer Nature remains neutral with regard to jurisdictional claims in published maps and institutional affiliations. 